\title{
Clinically relevant outcomes in dental clinical trials: challenges and proposals
}

Claudio Mendes PANNUTI(a)

Daniel Isaac SENDYK(a) (D)

Yasmin Teixeira das GRAÇAS(a)

Sandra Lie TAKAI(a)

Vicente de Paulo Aragão SABÓIA ${ }^{(b)}$

Giuseppe Alexandre ROMITO(a)

Fausto Medeiros MENDES(c)

(a) Universidade de São Paulo - USP, School of Dentistry, Department of Stomatology, São Paulo, SP, Brazil.

(b) Universidade Federal do Ceará - UFC, School of Dentistry, Department of Restorative Dentistry, Fortaleza, CE, Brazil

(c)Universidade de São Paulo - USP, School of Dentistry, Department of Pediatric Dentistry, São Paulo, SP, Brazil

Declaration of Interests: The authors certify that they have no commercial or associative interest that represents a conflict of interest in connection with the manuscript.

Corresponding Author:

Claudio Mendes Pannuti

E-mail:pannuti@usp.br

hitps://doi.org/10.1590/1807-3107bor-2020.vol34.0073

Submitted: Sep 2, 2019

Accepted for publication: Sep 22, 2019

Last revision: June 8, 2020
Abstract: The impact of clinical trials on patient care depends on the outcomes that they evaluate. In Dentistry, many trials use outcomes that are important to clinicians, but not to the patients. Thus, the aim of the present manuscript is to present an overview of the limitations, challenges, and proposals on the use of clinically relevant outcomes $(\mathrm{CRO})$ in dental trials. Clinically relevant outcomes are variables that directly measure how the patient feels, functions, or survives. Some CROs, such as tooth loss, implant failure, and restorations failure require many years to occur and the number of events is low. The adoption of these variables as primary outcomes results in challenges for the researchers, such as use of large sample sizes and long followup periods. Surrogate outcomes, such as biomarkers, radiographic measurements and indexes, are frequently used to replace CROs. However, they present many limitations, since the effect of the treatment on a surrogate does not necessarily reflect a change in the clinical outcome. Some proposals for the adoption of CROs are presented, such as the development of core outcome sets within each dental specialties and the organization of multi-center clinical trials.

Keywords: Clinical Trial; Treatment Outcome; Biomarkers.

\section{Introduction}

Well-designed and properly conducted randomized controlled trials (RCTs) provide the strongest level of evidence, when pertaining to questions on the efficacy of therapeutic or preventive interventions. ${ }^{1}$ Although many questions may arise in the mind of the researcher, the trial should be designed to properly answer only the primary question. This is the most important question that the researchers want to answer, and it should be stated in advance ${ }^{2}$. Trial objectives and design, sample size and the main conclusions of a trial are all based on this primary question.

In RCTs, participants are randomly assigned to study groups and followed-up. The effects of the intervention are observed and quantified by means of outcome variables (also called response variables, dependent variables, or endpoints). Some examples of outcome variables are blood sugar levels, survival, pain, and relief of symptoms. If randomization is adequate, study groups will be comparable in relation to known and unknown prognostic factors. Therefore, differences between groups 
regarding outcome variables can be attributed to the effects of the intervention. ${ }^{2}$

Most of the trials have several outcomes, which are classified as primary and secondary. The primary outcome is the one that answers the primary question of the study. It should be the outcome of greatest importance to health professionals, policy makers, funders and above all, to the patients. ${ }^{3,4,5}$ Further, sample size calculation is based on the primary outcome. ${ }^{4,5}$ All other outcomes are secondary. Secondary outcomes are additional dependent variables, which are hierarchically less important. ${ }^{6}$ Since study design and sample size are not based on the secondary outcomes, the analysis of these variables is normally only exploratory, and their results should be interpreted with caution.

Most textbooks and guidelines ${ }^{4,5,7}$ recommend the use of only one primary outcome, in order to avoid problems of multiplicity. ${ }^{8}$ Further, it is important that all outcomes are pre-specified, which means that they should be determined in the protocol before the start of the study, in a publicly accessible registry, such as ClinicalTrials.gov, Australian New Zealand Clinical Trials Registry or REBEC (Brazilian Clinical Trials Registry). The objective of pre-registration is to prevent publication bias and selective outcome reporting., ${ }^{9,10,11}$

The relevance of a clinical trial is directly related to its outcomes. However, most trials in Dentistry are focused in outcomes that are important to clinicians, but not to the patients. ${ }^{12,13}$ Trials that evaluate clinically relevant outcomes can change clinical practice and have an impact on patient care. Conversely, the use of unimportant or inadequate outcomes to answer the study question is a waste of resources, since it can overestimate or underestimate the effects of an intervention. Thus, the aim of this review is to present an overview of the literature considering limitations, challenges, and proposals in the use of clinically relevant outcomes in Dentistry.

\section{What are clinically relevant and surrogate outcomes?}

A clinically relevant outcome (CRO), also called direct, true or clinically meaningful outcome, is a variable that "directly measure how a patient feels, functions, or survives". ${ }^{14}$ In other words, CROs should reflect a tangible benefit to the patient. CROs are classified as objective and subjective outcomes. Objective (also called "hard") CROs are generally reported by the clinician and are not subjective, i.e., they are less dependent on interpretation. Some examples of objective outcomes are survival, death, hospital discharge, functional performance, or important clinical events such as myocardial infarction, stroke, or bone fracture. On the other hand, subjective CROs are also relevant, but they are reported by the patient. Some examples of subjective CROs are pain relief, patient acceptability of treatment, patient anxiety or health related quality of life. Subjective CROs intend to reflect patient's perception, and therefore, they are usually reported by the patients. Therefore, these types of outcomes are also called patient-reported outcome measures (PROMs), and they will be discussed in depth in another paper of this supplement. ${ }^{15}$

Although CROs are more meaningful for the patients, most objective CROs in Dentistry require many years to manifest and the number of events is usually low. Thus, they are frequently replaced by surrogate outcomes, in order to reduce sample size, length of follow-up and the costs of the trial. Surrogate outcomes are laboratory measures (biomarkers), radiographic images, or physical signs that are not themselves a direct measurement of the clinical endpoint. Rather, they are supposed to be a substitute of the clinically relevant outcome. ${ }^{3,16,17}$ Some examples are tumor size in oncology trials; blood pressure, blood cholesterol levels and carotid intima-media thickness in cardiovascular trials; and CD4 lymphocyte counts in AIDS trials.

Some examples of clinically relevant and surrogate outcomes used in Dentistry are shown in Table 1.

Fleming ${ }^{18}$ has categorized outcomes in four levels: level 1 is a clinically relevant outcome, level 2 is a validated surrogate, level 3 is a non-validated surrogate, but considered to be 'reasonably likely to predict clinical benefit'; and Level 4 is a correlate which is a measure of biological activity, but that 'has not been established to be at a higher level'. When it is not feasible to use a CRO, researchers 
Table 1. Clinically relevant and surrogate outcomes that are frequently used in Dentistry.

\begin{tabular}{|c|c|c|}
\hline Specialty area & Surrogate outcomes & Clinically relevant outcomes \\
\hline \multirow{3}{*}{ Endodontics } & Radiographic periapical healing & Tooth extraction as a result of endodontic problems \\
\hline & Number of microorganisms & Post-treatment discomfort / pain \\
\hline & & Oral-health related quality of life \\
\hline \multirow{5}{*}{ Oral implantology } & Peri-implant marginal bone loss & Implant loss \\
\hline & $\begin{array}{l}\text { Peri-implant clinical parameters (probing pocket } \\
\text { depth, bleeding on probing) }\end{array}$ & Aesthetic perception \\
\hline & Implant stability quotient & Oral-health related quality of life \\
\hline & Implant insertion torque & \\
\hline & Levels of immune-inflammatory markers & \\
\hline \multirow{4}{*}{ Oral surgery } & Wound healing & Pain relief \\
\hline & Swelling & Pain intensity \\
\hline & Trismus & Patient satisfaction \\
\hline & Levels of immune-inflammatory markers & Oral-health related quality of life \\
\hline \multirow{4}{*}{ Orthodontics } & Dental alignment (index) & Pain/discomfort \\
\hline & $\begin{array}{c}\text { Dental and skeletal changes in cephalometric } \\
\text { measurements }\end{array}$ & Treatment duration \\
\hline & Measurements of tooth movement in study casts & Patient perceptions of malocclusion \\
\hline & & Oral-health related quality of life \\
\hline \multirow{4}{*}{ Cariology } & Fluorescence emitted by caries lesions & Frankly cavitated caries lesions \\
\hline & Initial (white-spot) caries lesions & Caries lesions reaching the pulp \\
\hline & Radiographic images suggesting dental caries & Pain provoked by dental caries \\
\hline & & Tooth loss due to dental caries \\
\hline \multirow{2}{*}{ Pediatric dentistry } & Cortisol levels & Child Dental Anxiety scales \\
\hline & Pulse rate & Behavior rating scales (Frankl scale, for example) \\
\hline \multirow{5}{*}{ Periodontology } & Numbers of periodontal pathogens & Tooth loss \\
\hline & Levels of immune-inflammatory markers & Patient satisfaction \\
\hline & $\begin{array}{l}\text { Periodontal clinical parameters (probing pocket } \\
\text { depth, clinical attachment gain) }\end{array}$ & Post-treatment discomfort / pain \\
\hline & & Aesthetic perception \\
\hline & & Oral-health related quality of life \\
\hline \multirow{3}{*}{ Restorative dentistry } & Marginal discoloration & Restoration failure or loss \\
\hline & Marginal adaptation & Pain \\
\hline & Surface texture & Oral-health related quality of life \\
\hline
\end{tabular}

should adopt a surrogate that is at least validated (level 2 outcome). However, the validation of a surrogate is not a simple process. It must be demonstrated, preferably in a randomized trial, that the effects of the intervention on the surrogate reliably predicts a clinically important effect on a clinically relevant outcome.

\section{What are the limitations in the use of surrogate outcomes?}

Ideally, the surrogate outcome (e.g. numbers of CD-4 cells) should be in the only causal pathway of the clinical outcome (e.g. AIDS-related survival). Thus, the effect of the intervention on the surrogate 
should predict the effect on the clinical outcome. For example, theoretically, a treatment that increases the levels of CD-4 cells should increase the survival of AIDS patients.

However, in most of the cases: a) the surrogate is not in the same causal pathway that results in the clinical outcome; b) there are several causal pathways of the clinical outcome, but the intervention affects only the pathway mediated through the surrogate; c) there are several causal pathways of the clinical outcome, but the intervention affects pathways others than that mediated through the surrogate; or d) the intervention affects the clinical outcome through mechanisms that are independent of the disease process ${ }^{3}$. This is the reason why the adoption of surrogates in clinical trials can be associated with false positive or false negative results., ${ }^{3,16,19}$ For example, Fleming ${ }^{20}$ conducted a review of AIDS trials and observed that there was an increase in CD4 cell counts in 6 out of 7 trials in which treatment had no effect on survival. In another example, the DREAM trial demonstrated that Rosiglitazone significantly reduced blood glucose levels, but later on, the drug was withdrawn from the market because it increased the risk of myocardial infarction. ${ }^{21}$

In Dentistry, most of the trials have traditionally relied on surrogate outcomes. For example, in Periodontology, many antibiotics or laser trials have used number and percentage of periodontal pathogens as outcome variables. A randomized trial, ${ }^{22}$ have observed that adjunctive Nd:YAG laser irradiation significantly reduced the total number of subgingival bacteria of periodontitis patients, immediately after treatment, when compared to non-surgical periodontal treatment. However, after 6 months, there was no additional effect on clinical attachment gain. It is important to clarify that, although clinical attachment gain has been validated in cohort studies as a predictor of tooth loss, ${ }^{23,24}$ there was no validation in a randomized trial. In another example, adjunctive metronidazole and amoxicillin significantly decreases the number of sites with probing depth $\geq 5 \mathrm{~mm},{ }^{25,26}$ but the effect on tooth loss is not known. Sites with residual pockets $\geq 5 \mathrm{~mm}$ are predictive of tooth loss in cohort studies, ${ }^{27,28}$ but this surrogate has not been validated in randomized trials.

In Implant Dentistry, although there is no validation in a randomized trial, it is widely accepted that continuous marginal bone loss is a critical peri-implant condition and a threat to implant survival. In 1986, Albrektsson et al., ${ }^{29}$ established the success criteria for dental implants and proposed a reference of acceptable bone loss of $1.5 \mathrm{~mm}$ during the first year of loading followed by $0.2 \mathrm{~mm}$ yearly, which was, thereafter, showed in several long-term RCTs. The $6^{\text {th }}$ European Workshop of Periodontology, which was held in 2008, indicated that an increase in probing depth over time would be associated with bone loss around implants, spreading the use of periodontal parameters, such as probing depth and bleeding on probing as surrogate outcomes. ${ }^{30}$ However, the scientific evidence that supported this report statement is based on three animal model studies. A study with cynomolgus monkeys ${ }^{31}$ compared teeth and implants regarding the apical position of probe tips and concluded that probing measurements around implants and teeth were different, and even mild marginal inflammation was associated with deeper probe penetration around implants. Soft tissue around implants has also been described thicker than around teeth, based on human biopsies. ${ }^{32}$ An increase in probing depth around an implant does not necessarily mean that bone loss has occurred.$^{33}$ Rather, it could have been caused by a change in the inflammatory condition of the periimplant soft tissue. Few clinical studies have looked for correlations between bone loss and probing depth around implants. They concluded that this clinical parameter is of limited value in predicting future peri-implant bone loss. ${ }^{34,35,36,37}$ The use of these parameters as surrogate outcomes could lead to overdiagnosis and false positive findings of peri-implant pathology, which results in patients being subjected to unnecessary treatment.

The problem in using surrogate outcomes instead of CROs is also present in cariology. For example, a study investigated the benefits of fluoride varnish applications for dental caries prevention and management and involved 31 patients allocated to two groups. The primary outcome was the quantification of the fluorescence emitted by caries lesions using 
the Quantitative light-induced fluorescence method, a quantitative method, and the follow-up was only 6 months. The authors observed that that applications of fluoride varnishes presented benefits on the arrestment of white spot lesions compared to professional tooth cleaning. ${ }^{38}$ On the other hand, a cluster-randomized clinical trial investigating the effect of 3 annual applications of fluoride varnishes compared to no intervention, involved almost 3,000 participants followed-up for 36 months. The primary outcome was the number of decayed, missed or filled surfaces, and the authors did not observe differences between the groups. ${ }^{39}$

\section{Challenges in the use of clinically relevant outcomes in dentistry}

Objective CROs are rarely reported in randomized trials in Dentistry. A review ${ }^{13}$ analyzed 220 RCTs from in eight leading general and specialty dental journals. The authors observed that the majority of the outcomes were surrogates, such as periodontal measurements, biomarkers and radiological assessments. Only a minority were objective CROs, such as survival or longevity. Likewise, Tsichlaki and $\mathrm{O}^{\prime}$ Brien $^{12}$ analyzed 133 RCTs of orthodontic interventions in children and verified that the majority of the trials (63\%) measured morphologic features of malocclusion that did not reflect the patient perspective. A recent review ${ }^{10}$ evaluated outcome discrepancies in dental implant literature. Interestingly, only $38.8 \%$ of RCTs included in the study assessed clinically relevant outcomes. Among these, the most studied CROs were implant survival, aesthetic perception and oral-health related quality of life.

As stated above, objective outcomes (e.g. death, tooth loss, implant failure or restoration failure) are rare events, and may take many years to manifest. As a result, researchers are faced with some challenges when they choose an objective $\mathrm{CRO}$ as the primary outcome.

The first challenge is the required sample size to detect a clinically meaningful difference between groups, regarding the primary outcome. Most of the objective CROs is dichotomous, e.g. tooth loss (yes/no) or implant failure (yes/no). As such, they require larger sample sizes, when compared to continuous outcomes..$^{40}$ Moreover, for ethical reasons, new treatments in Dentistry cannot be compared with placebo or no treatment. Thus, they are frequently compared to the standard of care. As a result, the expected effect sizes are small, which is associated with even larger sample sizes.

Some trials in Periodontology have reported tooth loss as a secondary outcome. However, as far as we know, there is no RCT in Periodontology that adopted tooth loss as the primary outcome. The reason is the large required sample size. For example: according to a Systematic Review, up to $88 \%$ of periodontally treated and maintained patients do not experience tooth loss after a follow-up of a minimum of 5 years. ${ }^{41}$ Suppose that a group of researchers is testing a new antibiotic, and expect an effect size of 5\% in the primary outcome (no tooth loss). In other words, they expect that $93 \%$ of the test subjects (periodontal treatment with adjunctive antibiotics) will not present any tooth loss during the trial, when compared to $88 \%$ of the control subjects (periodontal treatment with placebo). In order to demonstrate the efficacy of the new antibiotic, 1074 patients would be required to have an $80 \%$ power of detecting, as significant at the $5 \%$ level, an increase in the primary outcome from $88 \%$ in the control group to $93 \%$ in the test group.

Likewise, Implant Dentistry trials that have "implant loss" or "implant failure" as a primary outcome would require large sample sizes in order to detect a clinically meaningful difference between groups. In a PubMed search, (July 30, 2019), 1022 randomized clinical trials reported implant loss as an outcome. The majority of them, however, did not identify the primary outcome or considered implant loss as a secondary outcome. The few studies that considered failure as the primary outcome were, mostly, underpowered.

Along the same lines, tooth survival was not reported as a standalone outcome in any RCT of prevention and management of dental caries. It was included as a composite outcome (e.g. DMTF) in approximately $35 \%$ of the trials, though ${ }^{42}$. Nevertheless, different from the examples for periodontal disease or implants, frankly cavitated caries lesions are perceived by the patients and have negatively affected 
the patients' quality of life. Therefore, the composite outcome including decayed, missed and filled teeth (DMF-T), or only cavitated caries lesions can be considered as a $\mathrm{CRO}$ to be used in clinical trials.

In Restorative Dentistry, however, most trials use agreed criteria, such as Ryge or FDI score systems, in order to assess the quality of the restoration. However, only a minority evaluate hard outcomes such as failure of the restoration as the primary outcome. ${ }^{43}$

A further challenge is the follow-up period. The number of events such as tooth loss, implant failure/ loss and failure of restorations is quite small and require a long time to manifest. It may take from 5 to 10 years to observe a significant number of these events in the experimental groups. Moreover, that leads to another challenge: retention of study subjects. Extended follow-up periods are associated with high attrition rates. This source of bias can compromise the validity of a trial, especially if one of the groups experience higher attrition rates. ${ }^{44}$ Moreover, it can result in a reduction in study power. For example, the Shortened Dental Arch (SDA) Study ${ }^{45}$ was a multicenter RCT that compared two treatments for replacement of lost molars: partial removable dental prosthesis (PRDP group) and no prosthetic extension after the second premolar (SDA group). The groups were compared regarding tooth loss after 10 years. Initially, 215 patients were randomized. After 10 years, because of losses to follow-up, only 79 and 71 patients remained in PRDP and SDA groups, respectively. After 10 years, 14 and 8 tooth losses were recorded in the PRDP and SDA groups, respectively. The difference was not significant $(p=0.49)$, mainly due to the reduced power. Some examples ${ }^{45,46,47,48,49}$ of RCTs that used objective clinically relevant outcomes can be observed in the Table 2 .

\section{Proposals for the use of clinically relevant outcomes in dentistry}

Even trials with statistically significant results may be meaningless if their outcomes are not relevant to stakeholders (patients, health professionals, policy makers and funders). In Dentistry, RCTs traditionally use and abuse of surrogate outcomes, such as number of microorganisms, adaptation of restorations and radiographic signs and measurements that do not translate into benefits for the patients. One possible solution for the problem of poor selection of trial outcomes is the development of Core Outcome Sets within each dental specialty.

Core outcome sets (COS) consist in agreed, standardized minimum group of outcomes that should be collected and reported in trials involving a particular condition (for example dental caries, periodontal disease or peri-implantitis). The process of creation of a COS involves a wide range of stakeholders, including the patient. Thus, it is more likely that they will identify clinically relevant outcomes. ${ }^{50}$ The COMET (Core Outcome Measures in Effectiveness Trials) $)^{51}$ initiative maintains a database of COS, which includes efforts in some dental areas, such as dental caries, periodontal disease, dental implants and orthodontics. There is a growing interest in the development of COS in Dentistry. ${ }^{42,52,53,54}$

As previously discussed, the assessment of objective CROs, such as tooth loss or implant failure, warrants larger sample sizes. However, a single-center study may not have capacity to enroll enough patients and achieve the required sample size. Multicenter clinical trials are needed to overcome this problem. The main advantage of multicenter trials is their capacity of enrolling a large number of study subjects in a shorter time, thus providing sufficient power to detect even small treatment effects..$^{55}$ An additional advantage of this kind of study is to increase the generalizability (external validity), as the study enrolls a more heterogeneous sample of subjects from different places. However, the complexity of the study increases, resulting in additional challenges, such as trial management. Management of multicenter trials requires a group of investigators, headed by the Principal Investigator (PI). The PI, co-investigators, and other experts, comprise the Steering Committee. On the other hand, the Data Monitoring Committee, comprised of individuals that are external to the study, is responsible for aspects such as safety monitoring and study integrity: (European Medicines Agency, 2005). In Dentistry, multicenter trials still represent a minority of all RCTs: a simple search in PubMed (August 10, 2019) revealed that they represent approximately $5 \%$ of the total number of trials. 
Table 2. Examples of randomized controlled trials in Dentistry that used objective clinically relevant outcomes but failed in showing statistically significant differences among the groups.

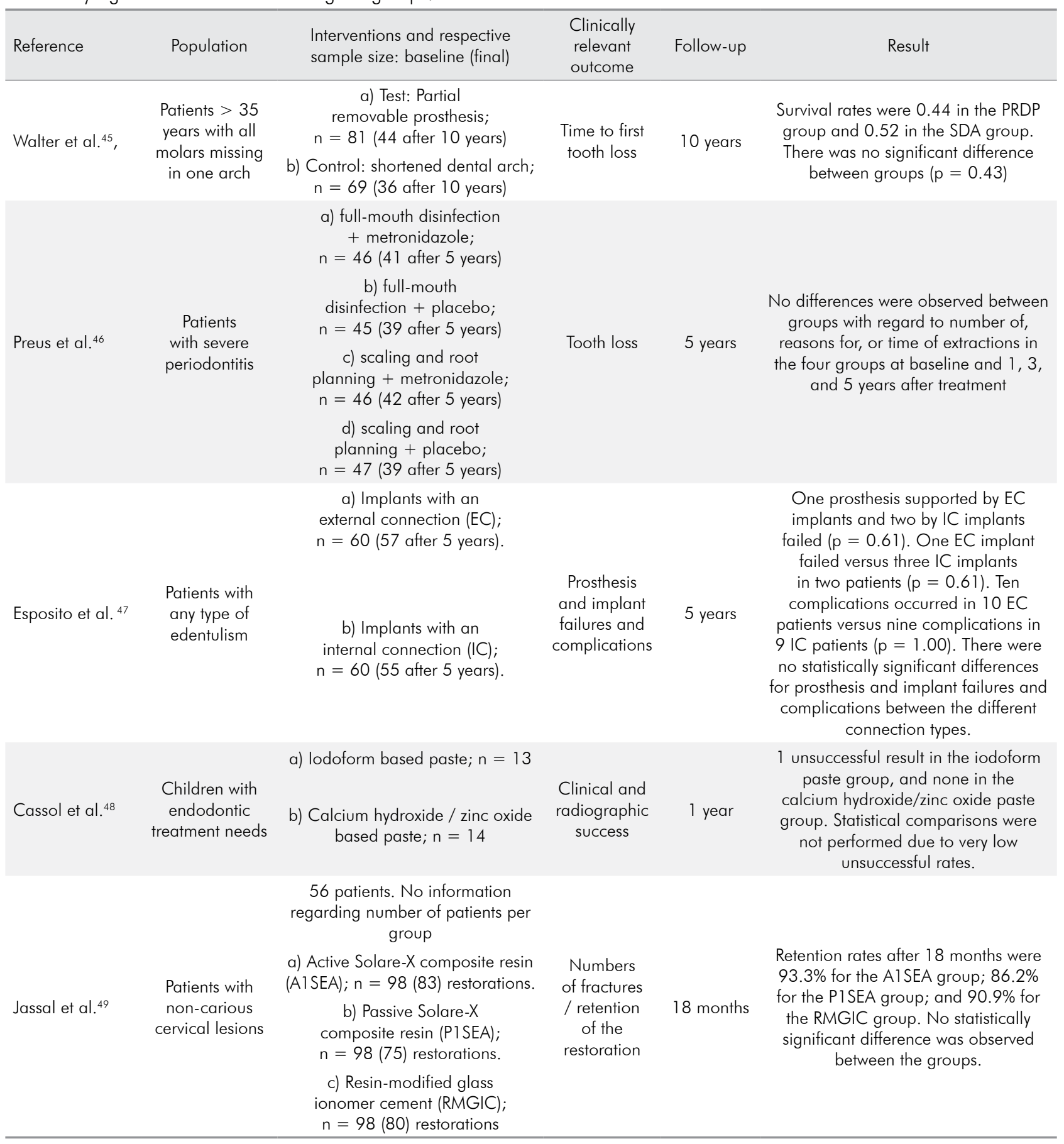

Researchers are encouraged to adopt clinically relevant outcomes as the primary outcome of a trial, in order to answer relevant questions. When the use of CROs is not possible, researchers should use a surrogate that is at least validated.

\section{Conclusion}

The adoption of objective CROs in Dentistry is not frequent, mainly due to the difficulties related to necessity of large sample size and duration of 
the studies. However, researchers should always opt to design clinical trials using outcomes that are relevant for the patients or other stakeholders. Alternatives to overcome these difficulties are the development of core outcome sets within each dental specialty and the organization of multicenter clinical trials. Dental associations, scientific community and sponsors are encouraged to organize larger studies.

\section{Acknowledgements}

Authors are indebted to the Scientific Committee of the meeting "Grandes Desafios em Pesquisa Clínica na Odontologia", in which the lecture that originated this manuscript was presented, to funding sources of the event (Coordination for the Improvement of Higher Education Personnel - CAPES \#88887.290888/2018-00 Edital 29/2018, Dean's Office for Research Studies / University of São Paulo - PRP/USP \#2018.1.852.23.5 and School of Dentistry Foundation / Foundation for Scientific and Technological Development of Dentistry - FFO/ Fundecto); and to Professor Giuseppe Alexandre Romito, editor-in-chief of Brazilian Oral Research $\mathrm{BOR}$, for agreeing with the publication of each eventderived lecture in this supplement. They declare no potential conflicts of interest with respect to the authorship and/or publication of this article.

\section{References}

1. Sackett DL. Rules of evidence and clinical recommendations on the use of antithrombotic agents. Chest. 1989 Feb;95(2 Suppl):2S-4S. https://doi.org/10.1378/chest.95.2_Supplement.2S

2. Friedman LM, Furberg CD, DeMets D, Reboussin DM, Granger CB. Fundamentals of Clinical Trials. 5th ed. New York: Springer; 2015. https://doi.org/10.1007/978-3-319-18539-2

3. Fleming TR, DeMets DL. Surrogate end points in clinical trials: are we being misled? Ann Intern Med. 1996 Oct;125(7):605-13. https://doi.org/10.7326/0003-4819-125-7-199610010-00011

4. Moher D, Hopewell S, Schulz KF, Montori V, Gøtzsche PC, Devereaux PJ, et al. CONSORT 2010 explanation and elaboration: updated guidelines for reporting parallel group randomised trials. BMJ. 2010 Mar;340 mar23 1:c869. https://doi.org/10.1136/bmj.c869

5. Chan AW, Tetzlaff JM, Altman DG, Laupacis A, Gøtzsche PC, Krleža-Jerić K, et al. SPIRIT 2013 statement: defining standard protocol items for clinical trials. Ann Intern Med. 2013 Feb;158(3):200-7. https://doi.org/10.7326/0003-4819-158-3-201302050-00583

6. O'Neill RT. Secondary endpoints cannot be validly analyzed if the primary endpoint does not demonstrate clear statistical significance. Control Clin Trials. 1997 Dec;18(6):550-6. https://doi.org/10.1016/S0197-2456(97)00075-5

7. ICH. ICH E9 note for guidance on statistical principles for clinical trials. Stat Med. 1999;18:1905-42.

8. Schulz KF, Grimes DA. Multiplicity in randomised trials I: endpoints and treatments. Lancet. 2005 Apr;365(9470):1591-5. https://doi.org/10.1016/S0140-6736(05)66461-6

9. Chan AW, Hróbjartsson A, Haahr MT, Gøtzsche PC, Altman DG. Empirical evidence for selective reporting of outcomes in randomized trials: comparison of protocols to published articles. JAMA. 2004 May;291(20):2457-65. https://doi.org/10.1001/jama.291.20.2457

10. Sendyk DI, Rovai ES, Souza NV, Deboni MC, Pannuti CM. Selective outcome reporting in randomized clinical trials of dental implants. J Clin Periodontol. 2019 Jul;46(7):758-65. https://doi.org/10.1111/icpe.13128

11. Koufatzidou M, Koletsi D, Fleming PS, Polychronopoulou A, Pandis N. Outcome reporting discrepancies between trial entries and published final reports of orthodontic randomized controlled trials. Eur J Orthod. 2019 May;41(3):225-30. https://doi.org/10.1093/ejo/cjy046

12. Tsichlaki A, O'Brien K. Do orthodontic research outcomes reflect patient values? A systematic review of randomized controlled trials involving children. Am J Orthod Dentofacial Orthop. 2014 Sep;146(3):279-85. https://doi.org/10.1016/i.ajodo.2014.05.022

13. Fleming PS, Koletsi D, O’Brien K, Tsichlaki A, Pandis N. Are dental researchers asking patient-important questions? A scoping review. J Dent. 2016 Jun;49:9-13. https://doi.org/10.1016/i.jdent.2016.04.002

14. Temple RJ. A regulatory authority's opinion about surrogate endpoints. In: Nimmo WS, Tucker GT, editors. Clinical Measurement in Drug Evaluation. New York: J Wiley; 1995.

15. Perazzo MF, Serra-Negra JM, Firmino RT, Pordeus IA, Martins-Júnior PA, Paiva SM. Patient-centered assessment: how to use them in dental clinical trials? Braz Oral Res. 2020;34(suppl 2):e075. https://doi.org/10.1590/1807-3107bor- 2020.vol34.0075

16. Fleming TR. Evaluating therapeutic interventions: some issues and experiences. Stat Sci. 1992 Nov;7(4):428-56. https://doi.org/10.1214/ss/1177011128 
Pannuti CM, Sendyk DI, Graças YT, Takai SL, Sabóia VPA, Romito GA, et al.

17. FDA.gov. Table of surrogate endpoints that were the basis of drug approval or licensure. Silver Spring: FDA; 2019 [cited 2019 May 30 ]. Available from: https://www.fda.gov/drugs/development-resources/table-surrogate-endpoints-were-basis-drug-approval-or-licensure

18. Fleming TR. Surrogate endpoints and FDA's accelerated approval process. Health Aff (Millwood). 2005 Jan-Feb;24(1):67-78. https://doi.org/10.1377/hlthaff.24.1.67

19. Fleming TR, Powers JH. Biomarkers and surrogate endpoints in clinical trials. Stat Med. 2012 Nov;31 (25):2973-84. https://doi.org/10.1002/sim.5403

20. Fleming TR. Surrogate markers in AIDS and cancer trials. Stat Med. 1994 Jul;13(13-14):1423-35. https://doi.org/10.1002/sim.4780131318

21. Cohen D. Rosiglitazone: what went wrong? BMJ. 2010 Sep;341 sep06 2:c4848. https://doi.org/10.1136/bmi.c4848

22. de Andrade AK, Feist IS, Pannuti CM, Cai S, Zezell DM, De Micheli G. Nd:YAG laser clinical assisted in class II furcation treatment. Lasers Med Sci. 2008 Oct;23(4):341-7. https://doi.org/10.1007/s10103-007-0482-6

23. Gilbert GH, Shelton BJ, Chavers LS, Bradford EH Jr. Predicting tooth loss during a population-based study: role of attachment level in the presence of other dental conditions. J Periodontol. 2002 Dec;73(12):1427-36. https://doi.org/10.1902/jop.2002.73.12.1427

24. Hujoel PP, Löe H, Anerud A, Boysen H, Leroux BG. The informativeness of attachment loss on tooth mortality. J Periodontol. 1999 Jan;70(1):44-8. https://doi.org/10.1902/jop.1999.70.1.44

25. Borges I, Faveri M, Figueiredo LC, Duarte PM, Retamal-Valdes B, Montenegro SCL, et al. Different antibiotic protocols in the treatment of severe chronic periodontitis: a 1-year randomized trial. J Clin Periodontol. 2017 Aug;44(8):822-832. 2017. https://doi.org/10.1111/jcpe.12721.

26. Mestnik MJ, Feres M, Figueiredo LC, Soares G, Teles RP, Fermiano D, et al. The effects of adjunctive metronidazole plus amoxicillin in the treatment of generalized aggressive periodontitis: a 1-year double-blinded, placebo-controlled, randomized clinical trial. J Clin Periodontol. 2012 Oct;39(10):955-61. https://doi.org/10.1111/j.1600-051X.2012.01932.x

27. Matuliene G, Pjetursson BE, Salvi GE, Schmidlin K, Brägger U, Zwahlen M, et al. Influence of residual pockets on progression of periodontitis and tooth loss: results after 11 years of maintenance. J Clin Periodontol. 2008 Aug;35(8):685-95. https://doi.org/10.1111/j.1600-051X.2008.01245.x

28. Graetz C, Plaumann A, Schlattmann P, Kahl M, Springer C, Sälzer S, et al. Long-term tooth retention in chronic periodontitis - results after 18 years of a conservative periodontal treatment regimen in a university setting. J Clin Periodontol. 2017 Feb;44(2):169-77. https://doi.org/10.1111/jcpe.12680

29. Albrektsson T, Zarb G, Worthington P, Eriksson AR. The long-term efficacy of currently used dental implants: a review and proposed criteria of success. Int J Oral Maxillofac Implants. 1986;1(1):11-25.

30. Heitz-Mayfield LJ. Peri-implant diseases: diagnosis and risk indicators. J Clin Periodontol. 2008 Sep;35(8 Suppl):292-304. https://doi.org/10.1111/j.1600-051X.2008.01275.x

31. Schou S, Holmstrup P, Stoltze K, Hiørting-Hansen E, Fiehn NE, Skovgaard LT. Probing around implants and teeth with healthy or inflamed peri-implant mucosa/gingiva. A histologic comparison in cynomolgus monkeys (Macaca fascicularis). Clin Oral Implants Res. 2002 Apr;13(2):113-26. https://doi.org/10.1034/j.1600-0501.2002.130201.x

32. Tomasi C, Tessarolo F, Caola I, Wennström J, Nollo G, Berglundh T. Morphogenesis of peri-implant mucosa revisited: an experimental study in humans. Clin Oral Implants Res. 2014 Sep;25(9):997-1003. https://doi.org/10.1111/clr.12223

33. Coli P, Christiaens V, Sennerby L, Bruyn H. Reliability of periodontal diagnostic tools for monitoring peri-implant health and disease. Periodontol 2000. 2017 Feb;73(1):203-17. https://doi.org/10.1111/prd.12162

34. Doornewaard R, Jacquet W, Cosyn J, De Bruyn H. How do peri-implant biologic parameters correspond with implant survival and periimplantitis? A critical review. Clin Oral Implants Res. 2018 Oct;29 Suppl 18:100-23. https://doi.org/10.1111/clr.13264

35. Dierens M, Vandeweghe S, Kisch J, Nilner K, De Bruyn H. Long-term follow-up of turned single implants placed in periodontally healthy patients after 16-22 years: radiographic and peri-implant outcome. Clin Oral Implants Res. 2012 Feb;23(2):197-204. https://doi.org/10.1111/j.1600-0501.2011.02212.x

36. Giannopoulou C, Bernard JP, Buser D, Carrel A, Belser UC. Effect of intracrevicular restoration margins on peri-implant health: clinical, biochemical, and microbiologic findings around esthetic implants up to 9 years. Int J Oral Maxillofac Implants. 2003 Mar-Apr;18(2):173-81.

37. Weber HP, Crohin CC, Fiorellini JP. A 5-yeahradiographic study of non-submerged dental implants. Clin Oral Implants Res. 2000 Apr;11(2):144-53. https://doi.org/10.1034/i.1600-0501.2000.110207.x

38. Tranaeus S, Al-Khateeb S, Biörkman S, Twetman S, Angmar-Månsson B. Application of quantitative light-induced fluorescence to monitor incipient lesions in caries-active children. A comparative study of remineralisation by fluoride varnish and professional cleaning. Eur J Oral Sci. 2001 Apr;109(2):71-5. https://doi.org/10.1034/i.1600-0722.2001.00997.x

39. Milsom KM, Blinkhorn AS, Walsh T, Worthington HV, Kearney-Mitchell P, Whitehead $H$, et al. A cluster-randomized controlled trial: fluoride varnish in school children. J Dent Res. 2011 Nov;90(11):1306-11. https://doi.org/10.1177/0022034511422063 
- Clinically relevant outcomes in dental clinical trials: challenges and proposals

40. Bhandari M, Lochner H, Tornetta P 3rd. Effect of continuous versus dichotomous outcome variables on study power when sample sizes of orthopaedic randomized trials are small. Arch Orthop Trauma Surg. 2002 Mar;122(2):96-8. https://doi.org/10.1007/s004020100347

41. Chambrone L, Chambrone D, Lima LA, Chambrone LA. Predictors of tooth loss during long-term periodontal maintenance: a systematic review of observational studies. J Clin Periodontol. 2010 Jul;37(7):675-84. https://doi.org/10.1111/j.1600-051X.2010.01587.x

42. Levey C, Innes N, Schwendicke F, Lamont T, Göstemeyer G. Outcomes in randomised controlled trials in prevention and management of carious lesions: a systematic review. Trials. 2017 Nov;18(1):515. https://doi.org/10.1186/s13063-017-2256-1

43. Opdam NJ, Collares K, Hickel R, Bayne SC, Loomans BA, Cenci MS, et al. Clinical studies in restorative dentistry: new directions and new demands. Dent Mater. 2018 Jan;34(1):1-12. https://doi.org/10.1016/i.dental.2017.08.187

44. Nunan D, Aronson J, Bankhead C. Catalogue of bias: attrition bias. BMJ Evid Based Med. 2018 Feb;23(1):21-2. https://doi.org/10.1136/ebmed-2017-110883

45. Walter MH, Dreyhaupt J, Hannak W, Wolfart S, Luthardt RG, Stark H, et al. The Randomized Shortened Dental Arch Study: Tooth Loss Over 10 Years. Int J Prosthodont. 2018 Jan/Feb;31(1):77-84. https://doi.org/10.11607/ijp.5368

46. Preus HR, Gjermo P, Baelum V. A Randomized Double-Masked Clinical Trial Comparing Four Periodontitis Treatment Strategies: 5-Year Tooth Loss Results. J Periodontol. 2017 Feb;88(2):144-52. https://doi.org/10.1902/jop.2016.160332

47. Esposito M, Maghaireh H, Pistilli R, Grusovin MG, Lee ST, Trullenque-Eriksson A, et al. Dental implants with internal versus external connections: 5-year post-loading results from a pragmatic multicenter randomised controlled trial. Eur J Oral Implantol. 2016;9 Suppl $1(2): 129-41$

48. Cassol DV, Duarte ML, Pintor AV, Barcelos R, Primo LG. lodoform Vs Calcium Hydroxide/Zinc Oxide based pastes: 12-month findings of a Randomized Controlled Trial. Braz Oral Res. 2019 Feb;33:e002. https://doi.org/10.1590/1807-3107bor-2019.vol33.0002

49. Jassal M, Mittal S, Tewari S. Clinical effectiveness of a resin-modified glass ionomer cement and a mild one-step self-etch adhesive applied actively and passively in noncarious cervical lesions: an 18-month clinical trial. Oper Dent. 2018 Nov/Dec;43(6):581-92. https://doi.org/10.2341/17-147-C

50. Prinsen CA, Vohra S, Rose MR, Boers M, Tugwell P, Clarke M, et al. How to select outcome measurement instruments for outcomes included in a "Core Outcome Set" - a practical guideline. Trials. 2016 Sep;17(1):449. https://doi.org/10.1186/s13063-016-1555-2

51. Comet Initiative. Database. 2019 [access: 2018 Aug 10]. Available from: http://www. comet- initiative. org/ studies/

52. Smaïl-Faugeron V, Fron Chabouis H, Durieux P, Attal JP, Muller-Bolla M, Courson F. Development of a core set of outcomes for randomized controlled trials with multiple outcomes_example of pulp treatments of primary teeth for extensive decay in children. PLoS One. 2013;8(1):e51908. https://doi.org/10.1371/journal.pone.0051908

53. Lamont TJ, Clarkson JE, Ricketts DN, Heasman PA, Ramsay CR. Core outcomes in periodontal trials: study protocol for core outcome set development. Trials. 2017 Sep;18(1):436. https://doi.org/10.1186/s13063-017-2169-z

54. Tsichlaki A, O'Brien K, Johal A, Marshman Z, Benson P, Colonio Salazar FB, et al. Development of a core outcome set for orthodontic trials using a mixed-methods approach: protocol for a multicentre study. Trials. 2017 Aug;18(1):366. https://doi.org/10.1186/s13063-017-2098-x

55. Chung KC, Song JW. A guide to organizing a multicenter clinical trial. Plast Reconstr Surg. 2010 Aug;126(2):515-23. https://doi.org/10.1097/PRS.0b013e3181df64fa 